\title{
IDENTIFICATION OF THE MEAT OF THE DIFFERENT SPECIES OF BIRDS USING THE GUANTITATIVE ANALYSIS OF THE DESCRIPTIVE SHAPES OF THE CRYSTALLINE MYOSIN
}

\author{
Helal, A. D.*; Abu-Arab, N. M. A.**; \\ Salama, M. A.*** and El-Shawarby, R.**** \\ *Animal Health Research Institute ( Buffalo Dis. Dept. ), \\ **Animal Health Research Institute ( Banha Bramch, Food and Meat Hygiene Dept. ), \\ ***Fac. of Science ( Zoology Dept., Zag. Univ. ), \\ ****Fac. of Vet. Med. ( Banha Univ., Forensic Med. \& Toxic. Dept.)
}

\begin{abstract}
Myosin is the main contractile protein of the muscles. Crystalline myosin could be Prepared in the form of needle crystals. The different rearrangements of such needles together may forming different descriptive shapes which may be used for meat identification of bird species. Three fresh thigh muscles from each species of the five studied species of birds were homogenized for preparation of their crystalline myosins. The results indicated presence of nine different descriptive shapes in the studies species of birds, the (most) characteristic shapes and their percentages were recorded for each species as following : for Fattening broiler chickens : Large thick needle - like crystals (18.9\%) and contacted myosin crystals (5.22\%), for Native broiler chickens: Branched point - like crystals (5.93\%), large thick needle - like crystals (14.23\%)and Contacted myosin crystals (8.51\%), for Pigeons : Long branched stem - like crystals (16.97\%), Short branched stem- like crystals (21.86\%), for Ibises : X - litter shape - like crystals, (5.01\%) and Contacted myosin crystals (15.93\%), and for Ducks : Frond shape - like crystals (3.57\%), $\mathrm{K}$ - litter shape - like crystals (6.85\%), and Short branched stem - like crystals (20.06\%). For more improvement of such method for further confirmation of species, it could be suggested that the myosin (crystals, solutions, molecules and subfraqment -1-crystals) should be studied by different ways to understanding the species differences in their (total compositions and amino acids either contents or sequences) in the presence of fixed in vivo and in vitro factors, Also, the negative staining with fixation of different crystalline myosins for electron microscopical study and the $x$ - ray diffraction patterns analysis on myosin crystals and the crystals of myosin subfragment1 should be studied for further confirmation.
\end{abstract}

\section{INTRODUCTION}

Mysin is a very large globular protein and could isolated from rabbit skeletal muscle and bovine brain (Toma and Berl, 1982). The molecule of myosin contains two identical major chains and four light chains. Structurally 
its molecule consisted of two globular regions and a tail - like appendage which joined to each globular region, each appendage is arranged as one strand which in turn composed of a double stranded alpha - helix. Myosin was bound (in a polymerized from) with actin to form actionomyosin (a protein complex of 3 - myosin molecules united with 1 - actin molecules) in case of muscle contraction (Harper et. al., 1979). The myosin molecules are aggregated coaxially (coaxial association) to become visible in the form of needle shaped crystals, and sometimes in the form of long threads or fibrils (Gyorgyi, 1943). Some needles or fibres are arranged radially in aggregated beautiful crystals (Hartshorne and Stuart, 1952), but Charles (1966) found that the crystals of myosin from muscles are imperfect crystalline arrangement. Siemankowski and Zobel (1976) examined the aggregated myosin of Rabbit's skeletal muscle and Lobster abdominal muscle by electron microscopy, they found that myosin aggregates of Rabbits formed elongated spindle shaped filaments, but the Lobster myosin aggregates formed short dumbbell shaped filaments.

Crystalline myosin prepared form the skeletal muscle of Rabbit in the form of microscopical visible needle - like crystals, which gave a silky sheen to the myosin crystal suspension (Oser (1979). Helal (1987) Prepared the crystalline myosin from the skeletal muscles of domestic animals as needle - like crystals of different descriptive shapes of aggregations as: Frond shape (Buffaloes), Palm-tree (Donkeys), Brush- like (Cats), Thin branched stem like crystals (Camels), Thick branched stem- like crystals ( Sheep), Budding crystals
(Dogs) and Small branched stem like crystals (Rabbits).

The crystalline myosin is an old finding since (1943) by Gyorgyi, who could firstly prepared and described it as a beutifull needles, but the arrangement and rearrangement of such needles found to be affected by many factors such as the amount of C- protein (Moose, 1973 and Offer, 1973), The divalent cations $\left(\mathrm{Mg}^{2+}\right.$ and $\left.\mathrm{Ca}^{2+}\right)$ (Wachaberger and pepe, 1980), the degree of protonation of imidazoloe groups of histidine amino acids in different species, the conditions of myosin solutions of different species ( $\mathrm{PH}$, ionic strength and the intrensic nature of myosin molecules) (Siemankowski and Zobel, 1976). Such factors may be affected by the different intrensic metabolic chemical processes which of coarse may differed from species to another with different degrees, which in turn affecting the possible differences of aggregations of myosin molecules to give at the end different shapes of aggregations such as described for Rabbits (elongated spindles) and for Lobster (short dumbbell filaments) as previously described by Siemankowski and Zobel (1976). So the target from the current study is to obtain different descriptive shapes for different species of birds parallel to that achieved for domestic animals but with slight improvement to be in a quantitative manner, as a trial for further identification of meat of the different species of birds by a cheap manner.

\section{MATERIAL \& METHODS}

\section{A) Chemicals :}

Potassium chloride (0.3M), Potassium chloride (2M), Dibasic potassium phosphate $\left(\mathrm{K}_{2} \mathrm{HPO}_{4}\right)(0.25 \mathrm{M})$, Potassium Dihydrogen 
phosphate $\left(\mathrm{KH}_{2} \mathrm{PO}_{4}\right)(0.25 \mathrm{M})$, Tripotassium orthophosphate $\left(\mathrm{K}_{3} \mathrm{PO}_{4} \cdot \mathrm{H}_{2} \mathrm{O}\right)(0.15 \mathrm{M})$, Diluted sulphuric acid (dil. $\left.\mathrm{H}_{2} \mathrm{O}_{4}\right)(0.5 \mathrm{ml}+99.5 \mathrm{ml}$ deionized water), Diluted potassium hydroxide (dil. $\mathrm{KOH})(0.55 \mathrm{gmKOH}+100 \mathrm{ml}$ deionized water), Deionized water (100 liters) (was kindly supplied from Benha Company for Electrical Industries( for Preparation of all solutions),

N.B. : all chemical solutions, containers, glasses are prepared or washed using deionized water

\section{B) Equipments :}

Glass microfiber filter paper (GF/F) (Whattman laboratory membrane filters) : $7 \mathrm{~cm}$ diameter, with ultra- fine filter and with retention down to $7 \mu \mathrm{m}$ liquid., Digital PH-meter, centrifuge, digital balance, Homogenizer, high power light microscope.,Glasses : (Glass rods, pipettes, graduated glass containers, slides and covers, buchner funnel) Scalpels, scissors, clean gauze, canada balsam and crushed ice.

\section{C) Muscle Samples :}

Thigh muscle samples from 3- birds of the five studied species of birds are freshly obtained from each of the different species of apparently healthy adult male birds : ducks, broiler Chickens (Native and fattening), pigeons and Ibises (Ibis ibis) directly after their slaughtering without any heat treatment of slaughted birds, the muscle samples of each species are put on crushed ice (for cooling) till experimentation in the same day (within 12hours)

\section{D) Methods :}

The method of preparation of crystalline myosin was carried out according to Oser
(1979) as following :

1- The cooled thigh muscle samples (of 3birds) are minced by homogenizer.

2- 37.5gm of mixed minced muscle (Free from fat and connective tissue) was taken on glass container.

3 - Add to the minced muscles $125 \mathrm{ml}$ of $\mathrm{Kcl}$ $(0.3 \mathrm{M})$ with mixing then add $125 \mathrm{ml}$ of $\mathrm{K}_{3}$ po $4 . \mathrm{H}_{2} \mathrm{O}(0.15 \mathrm{M})$ and mixed well to give the (meat extract).

4- The $\mathrm{PH}$ of the above meat extract was adjusted to 6.5 (using dil. $\mathrm{H}_{2} \mathrm{SO}_{4}$ or dil. $\mathrm{KOH}$ )

5- The meat extract was left in the refregerator for 15 minutes, with gentle stirring.

6- Transfer the meat extract to cylinder (1-litre capacity, and $500 \mathrm{ml}$ of cooled deionized Water was added) to give the diluted- meat extract.

7- The diluted - meat extract was then strained with sevenal layers of clean guaze.

8- The strained meat extract was then diluted with cold deionized water till final volume of $1500 \mathrm{ml}$.

9- The container containing the strained and diluted meat extract was put on crushed ice for 2-3 hours (without stirring or shaking).

10- The supernatant clear solution was carefully siphoned off .

11- The remaining precipitated meat extract was contrifugated (3000r.p.m.) to obtaining the "precipited proteins" at the bottom of the large centrifugation tubes after discarding the supernatant clear fluid.

12- The precipitated proteins are dissoloved by adding $7.5 \mathrm{ml}$ of $\mathrm{Kcl}(2 \mathrm{M})$ with stirring. 
13- A mixture of $3.75 \mathrm{ml}$ of $\mathrm{K}_{2} \mathrm{HPO}_{4}$ $(0.25 \mathrm{M})+3.75 \mathrm{ml}$ of $\mathrm{KH}_{2} \mathrm{PO}_{4}(0.25 \mathrm{M})$ (buffer solution) was added to the above dissolved precipitated proteins.

14- Cold deionized water was added to the above precipitated protein solution till the final volume of $37.5 \mathrm{ml}$.

15- The $\mathrm{PH}$ of this protein solution is adjusted to 6.6-6.8 (The ionic strength $=$ $0.5)$.

16- The protein solution then was centrifugated (at 3000r.p.m.) for 10 minutes to separate the ( supernatant myosin solution) from the other muscle protein which precipitated at the bottom.

17- The supernatant myosin solution was gently collected and filtered through buchner Funnel using the Glass microfiber filter paper $(G F / F)$, this filtration was done for further separation and clarification of the myosin solution, where the myosin could penetrated through the pores of the glass microfiber filter paper.

18- to the filtered myosin solution, add $30 \mathrm{ml}$ of cold deionized water with gentle stirring and cooling.

19- The diluted myosin solution was strongly centrifugated (at 5000r.p.m.) for 15 minutes (to remove the precipitated actomyosin), then the supernatant myosin solution was collected in clean dry glass container. The myosin crystals was found in this solution and may examined at this point, but $500 \mathrm{ml}$ of cold deionized water may slowly added (within 10-minutes) to the concentrated crystalline myosin solution with continuous and gentle stirring for more aggregation of myosin molecules into crystal- line needle forms, to be microscopically examined.

20- The different descriptive shapes are then quantitatively counted in each slides by a method similar to the differential leucocytic count according to Schalm et. al. ( 1975), to determine the percentage of each descriptive shape in relation to the other Shapes in the same species through counting 100 crystals in the slide, five or more slides are examined, and the mean percentage $( \pm \mathrm{SE})$ for each descriptive shape could be calculated for the quantitative determination of the most frequent characteristic descriptive shapes for each species.

N.B.: One drop of myosin solution was gently put on clean dry slide for microscopical examination, Canada balsam may enclose the boundary of cover slide after microscopical examination to prevent desiccation of the crystalline myosin suspension which may kept( in the refrigerator, 4C) unchanged for $24 \mathrm{hrs}$ or more after preparation .Also, the myosin crystal suspension should be kept in previousely sterilized clean dry glass containers at 4_C for further examinations.

\section{RESULTS}

A) General Analysis of the Different Descriptive Shapes of the Different Species of Birds:

The results revealed presence of nine different descriptive shapes which distributed in the studied five species of birds (Table, 1) as the following:

(1) Large thick needle - like crystals:

- Description : they are single thick and 
long straight needle crystals. (almostly nonbranched)

- Frequency : Such crystals are detected by the higher percentage in the fattening broilers (18.91\%) and pigeons (18.05\%). The medium percentage $(14.22 \%)$ in Native broilers and the lowest percentages (11.2\%) by Ibises (Fig.: 1,2,6,7,9,13and 17).

\section{(2) Small thin Needle - like Crystals :}

- Description : They are present in very small and irregularly scattered thin needles, they may be found singly or in a groups close to each other or even weekly attached joining irregularly small shapes that could not be described.

- Frequency : the higher percentage of the small needles are detected in Ducks $(62.74 \%)$ and fattening broilers $(60.4 \%)$, the medium percentages could be detected in the Native broiler chickens $(49.77 \%)$ and in the pigeons $(37.91 \%)$ the lower percentages could be detected in Ibises ( 25.57\%)(Fig.20)

(3) Short Branched Stem-like Crystals :

- Description : Such type of crystals is the most beautiful one, it resemble short stem of plant (without root) and they branched into two or more primary branches. One or more of the primary branches may subdivided into two or more secondary branches.

- Frequency : The higher percentages of short branched stem Crystals are detected in Ibises $(25.16 \%)$.The medium percentages are detected in pigeons (21.86\%), Ducks $(20.06 \%)$ and in the Native broiler chickens (11.42\%). The lower percentages was detected only in the Fattening broiler chickens $(2.81 \%)$ (Fig.
$4,9,15,18$, and 19$)$.

(4) Long Branched Stem- like Crystals :

- Description : These crystals resemble short branched stem like crystals, but with long stems, and also branching resemble the short one.

- Frequency : The higher percentage of long crystals are detected in Pigeons (16.969\%), followed by Ibises (13.36\%) them the lowest percentage was detected in Fattening broilers (2.52\%) (Fig.8,9,10 and 11).

\section{(5) Branched Point - like Crystals}

- Description : As one point from which many thick needles arised in different Directions.

- Frequency : Such crystals are detected in only one species of birds (Native broilers) and could be found also by small percentage $(5.93 \%)$, but could not be detected in other species of birds (Fig. 5 and 6).

\section{(6) K-Litter shape -like crystals}

- Description : Such crystals resembling the litter $-\mathrm{k}$ in their shape, but in some cases one or more of the four primary branches of the $\mathrm{k}$ - shape may subdivided into more smaller secondary branches.

- Frequency : The higher percentage was detected in ducks ( $6.85 \%$ ), but it decreases in the other species, as the percentages was $3.75 \%$ in Ibises , in native broilers was $3.24 \%$, in pigeons was $2.71 \%$ and in fattening broilers was $2.37 \%$. ( Fig. 11,16 and 17).

\section{(7) X- litter shape - like crystals :}

- Description : They resemble the litter - $\mathrm{x}$ in their shapes, but (as in k-shape) some of the four, primary branches may subdivided 
into smaller secondary branches.

- Frequency : The X- litter shape crystals could only be detected in Ibises by percentage of $5.01 \%$ ( Fig. 12,13,14).

\section{(8) Frond shape -like crystals :}

- Description : This shape resembling one of the upper branches of the palm treethat carrying regularly arranged straight leaves on both sides of the branch.

- Frequency : This type of crystals is rarely detected and found by small percentages in two species. In ducks its percentage was $(3.57 \%)$, but in fattening broilers by percentage of $0.723 \%$ (Fig. 15).

\section{(9) Contacted Myosin Crystals:}

- Description : Two similar or different crystals may united with each other to forming one compound crystal.

- Frequency : The higher percentages of contacted crystals was detected in Ibises (15.93\%) followed by native broilers $(8.51 \%)$, ducks (6.78\%), pigeons (6.48\%), and the least percentage in fattening broilers $(5.22 \%)$ (Fig.3,4,10, and 14).

\section{DISCUSSION}

The basic lines for the descriptions of the different obtained shapes of the crystalline myosins of the studied species of birds in the present study depend on the following Basis: the first depend on the fact that the scientific crystallographic name of all crystalline myosins of birds is "Needle crystals" according to Gyorgyi (1943) and Oser (1979), the second is the descriptions of the different forms of needle crystal aggregations (which are formed as a result of different rearrangements of such needles) to be described according to their resemblance to the natural objects following Siemankowski and Zobel (1976) and Helal (1987) in order to differentiate the different descriptive shapes according to species, the third base is the quantitative counting of different shapes in each species (differential myosin crystal counts) following the same method of the differential leucocytic count which used to determining the percentages of different types of leucocytic cells according to their shapes (Schalm, 1975) in order to determine the percentages of the different descriptive shapes of myosin crystals for each species of birds, to be used as normal patterns of percentages for each species as recorded in (table, 1), the fourth base is to extracting or concluding the (most) characteristic shapes for each species according firstly to the specific shapes for each species and secondly to the percentage specific shapes within each species as shown in (table, 2).

The current study revealed presence of nine types of different descriptive shapes distributed in the five different species of birds as following : for Fattening broilers chickens (large thick needles, contacted crystals), Native broilers chickens (branched point crystals, large thick needles and contacted crystals), for Pigeons (long branched stem like crystals and X - litter shape like crystals), for Ducks (small branched stem like crystals, K- litter shape like crystals and frond shape - like crystals), and for Ibises (X- litter shape like crystals and contacted myosin crystals), in addition to the small needle crystals which found in all species of studied birds by large percentages. Such nine different shapes of myosin crystals perhaps attributed to the fact that the myo- 
sins of different species of birds are existed in polymorphic forms according to their different electrophoretic patterns of myosin light chains (Locker and Hagyard, 1968, Perrie and Perry, 1970 and Pette and Schnez, 1977).

With high microscopic magnification (400) as in fig. (12 and others), the segment of a crystal itself appears to be composed of finer needles associated and compacted parallel with each other as a bundle. Gyorgyi (1943) firstly described such figure and mentioned that the myosin particles aggregated on the same axis (coaxial associatinon) forming needles which appear as bundles of finner needles, and this reflecting the need for future examination of myosin crystals with electron microscope.

The long crystals in the present study in the form of "long branched stem - like crystals" are detected in Ibises and Fattening and Native broiler chickens. Moose (1978) and Offer (1973) observed that the C- protein may be required for the formation of the elongate filaments in vivo. The divalent cations $\left(\mathrm{Mg}^{2+}\right.$ and $\mathrm{Ca}^{2+}$ ) are markedly affected the mophology and length of myosin aggregates (Whachaberger and Pepe, 1980), so that a future study should be tried for each species with constant serum and muscle $\mathrm{Mg}$ and Ca- concentrations to recognize the more definite percentages of different shapes in the different species. Siemankowski and Zobel (1976) mentioned that the aggregated mosin of Rabbits as artificial thick filaments, which forming elongate spindles, as the aggregation of rabbit myosin may involve protonation of imidazole groups of the histidine amino acids and the morphology and size of aggregated myosins depended on the myosin solution conditions (e.g.PH, ionic strength and the composition and the intrinsic nature of the myosin molecules).

Biochemical studies (as PCR and other methods) on the myosin (molecules, solutions and crystals) and myosin light chain (myosin subfragment- 1 crystals) should be carried out to recognizing the differences in their compositions, amino acid contents and amino acid sequences. Such studies should be carried out with fixed factors, such factors of special interest are in vivo factors as (nutritional, breed, age, sex, healthy status and the fixed normal concentration of serum and muscle magnesium and calcium elements of each species ), and in vitro factors ( as $\mathrm{PH}$ and ionic strength of myosin solutions in all species ) in order to understanding and reflecting the intrinsic causes of the different descriptive shapes in different species.

The use of crystalline myosins for meat identification of the species need further improvements, for such purposes, the following ideas are suggesting : the negative staining of myosin crystals with uranyl acetale (Huxley and Zubay, 1960) or stained with $2 \%$ potassium silicotungestate or with $2 \%$ potassium phosphotungstic acid (Unwinn, 1975- A), then fixation with glucose solution (1-0.75\%) for electron microscopical study (Unwinn, 1975B) to differentiate the myosin crystals of different species. Also, the analysis of the X- ray diffraction patterns should be tried with such microcrystals of myosins and /or with crystals of myosin subfragment -1 ( Rayment and Winkelmann-1984) such as recorded for the 
microprotein crystals of Thermitase protein which isolated from the culture medium of Thermoactinomyces vulgaris (Sherman et. al., 1981).

Based on the current study, it could be concluded that the species identification using crystalline mosins could be achieved through partially the (most) species specific characteristic shapes and partially through the percentages of shapes within each species as following : for Fattening broiler chickens : large thick needle- like crystals $(18.91 \%)$ and contacted myosin crystals (5.22\%), for Native broiler chickens : Branched point like crystals (5.93\%), large thick needle- like crystals $(14.23 \%)$ and contacted myosin crystals (8.51\%), for Pigeons : long branched stem like crystals (16.97\%) and short branched stem - like stals $(21.80 \%)$ for Ibises : X- litter shape like crystals $(5.01 \%)$ and contacted myosin crystals (15.93\%), and for Ducks : short branched stem - like crystals $(20.06 \%)$, frond. Shape - like crystals $(3.57 \%)$ and K- litter shape like crystals $(6.85 \%)$. For the problem of presence of some similar shapes between species (which can partially solved by their percentages) and for the more improvement of such method for further confirmation, the following ideas could be suggested : the myosin (molecules, solutions, crystals and the crystals of myosin subfragment-1) should be studied to understanding the species difference in their compositions amino acids contents, and amino acids sequences in the presence of fixed in vivo and in vitro factors.The negative staining of myosin crystals and their fixation for electron microscopical studies of the crystal segments of different species, also the analysis of $\mathrm{X}$ - ray diffraction patterns on crystals of myosin and its subfragment-1 crystals should be investigated. 
Table (1) : The Quantitative Analysis (Means \pm SE) of the Different Descriptive Shapes of the Crystalline Myosins of Thigh Muscles of the Different Species of Birds .

\begin{tabular}{|l|c|c|c|c|c|}
\hline \multicolumn{1}{|c|}{ Species é } & $\begin{array}{c}\text { Fattening } \\
\text { Broilers. } \\
\text { Chickens }\end{array}$ & $\begin{array}{c}\text { Native } \\
\text { Broilers } \\
\text { Chickens }\end{array}$ & Pigeons & Ibises & Ducks \\
\hline (1) Large thick Needle like crystals(\%) & $\begin{array}{c}18.918^{*} \\
\pm 3.136\end{array}$ & $\begin{array}{c}14.226^{*} \\
\pm 1.832\end{array}$ & $\begin{array}{c}18.058 \\
\pm 1.356\end{array}$ & $\begin{array}{c}11.20 \\
\pm 1.061\end{array}$ & 0.00 \\
\hline (2) Small thin Needle like crystals(\%) & 60.418 & 50.734 & 33.918 & 25.570 & $62.79 \pm$ \\
& \pm 5.371 & \pm 4.2 .2 & \pm 1.732 & \pm 0.551 & 2.77 \\
\hline (3) Short Branched stem like crystals(\%) & 9.812 & 11.426 & $21.86^{*}$ & 25.164 & $20.06^{*}$ \\
& \pm 2.12 & \pm 1.643 & \pm 1.43 & \pm 1.042 & \pm 3.10 \\
\hline (4) Long Branched Stem like crystals(\%) & 2.528 & 5.928 & $16.968^{*}$ & 13.366 & 0.00 \\
& \pm 0.915 & \pm 0.645 & \pm 0.766 & \pm 0.150 & \\
\hline (5) Branched point like crystals(\%) & 0.00 & $5.932^{*}$ & 0.00 & 0.00 & 0.00 \\
& & \pm 0.645 & & & \\
\hline (6) k- litter shape like crystals(\%) & 2.378 & 3.244 & 2.712 & 3.756 & $6.85^{*}$ \\
& \pm 0.911 & \pm 0.715 & \pm 0.097 & \pm 0.786 & \pm 0.82 \\
\hline (7) X- litter shape like crystals(\%) & 0.00 & 0.00 & 0.00 & $5.010^{*}$ & 0.00 \\
& & & & \pm 1.178 & \\
\hline (8) Frond shape-like crystals(\%) & 2.378 & 3.244 & 2.712 & 3.756 & $6.85^{*}$ \\
& \pm 0.911 & \pm 0.719 & \pm 0.097 & \pm 0.786 & \pm 0.82 \\
\hline (9) Contacted Myosine crystals(\%) & $5.223^{*}$ & $8.51 *$ & 6.484 & $15.934^{*}$ & 6.78 \\
& \pm 1.277 & \pm 1.84 & \pm 1.29 & \pm 1.089 & \pm 1.36 \\
\hline
\end{tabular}

N.B. $: *=a$ most characteristic descriptive shape in this species. 
Table (2) : The (Most) characteristic Descriptive Shapes of the crystalline Myosins of The Five Species of Birds.

\begin{tabular}{|c|c|c|}
\hline Species & $\begin{array}{l}\text { The (Most)Characteristic } \\
\text { Descriptive species specific } \\
\text { crystal shapes ( with their } \\
\text { percentages ) }\end{array}$ & Figures \\
\hline \multirow[t]{2}{*}{ Fattening Broiler Chickens } & $\begin{array}{l}\text { (1)Large thick needle- like } \\
\text { crystals }(18.92 \%)\end{array}$ & 1and 2 \\
\hline & $\begin{array}{l}\text { (2)contacted myosin } \\
\text { Crystals }(5.22 \%)\end{array}$ & 3 and 4 \\
\hline \multirow[t]{3}{*}{$\begin{array}{l}\text { Native Broiler } \\
\text { Chickens }\end{array}$} & $\begin{array}{l}\text { (1)Branched point-like } \\
\text { crystals }(5.93 \%)\end{array}$ & 5 and 6 \\
\hline & $\begin{array}{l}\text { (2)Large thick needle-like } \\
\text { crystals }\end{array}$ & 6and 7 \\
\hline & $\begin{array}{l}\text { (3)contacted myosin Crystals } \\
(8.51 \%)\end{array}$ & 7 \\
\hline \multirow[t]{2}{*}{ Pigeons } & $\begin{array}{l}\text { (1) Long branched stem- like } \\
\text { crystals }\end{array}$ & $8,9,10$ and 11 \\
\hline & $\begin{array}{l}\text { (2)Short branched stem- like } \\
\text { crystals }(21.86 \%)\end{array}$ & 9 \\
\hline \multirow[t]{2}{*}{$\begin{array}{l}\text { Ibises } \\
\text { (Ibis ibis) }\end{array}$} & $\begin{array}{l}\text { (1)X- litter shape- like } \\
\text { crystals }(5.01 \%)\end{array}$ & 12,13 and 14 \\
\hline & $\begin{array}{l}\text { (2)Contacted myosin crystals } \\
(15.93 \%)\end{array}$ & 14 \\
\hline \multirow[t]{3}{*}{ Ducks } & $\begin{array}{l}\text { (1)Frond shape-like crystals } \\
(6.85 \%)\end{array}$ & 15 \\
\hline & $\begin{array}{l}\text { (2)K-litter shape-like crystals } \\
(6.85 \%)\end{array}$ & 16 and 17 \\
\hline & $\begin{array}{l}\text { (3)Short branched stem-like } \\
\text { crystals }(20.06 \%)\end{array}$ & 18 and 19 \\
\hline
\end{tabular}




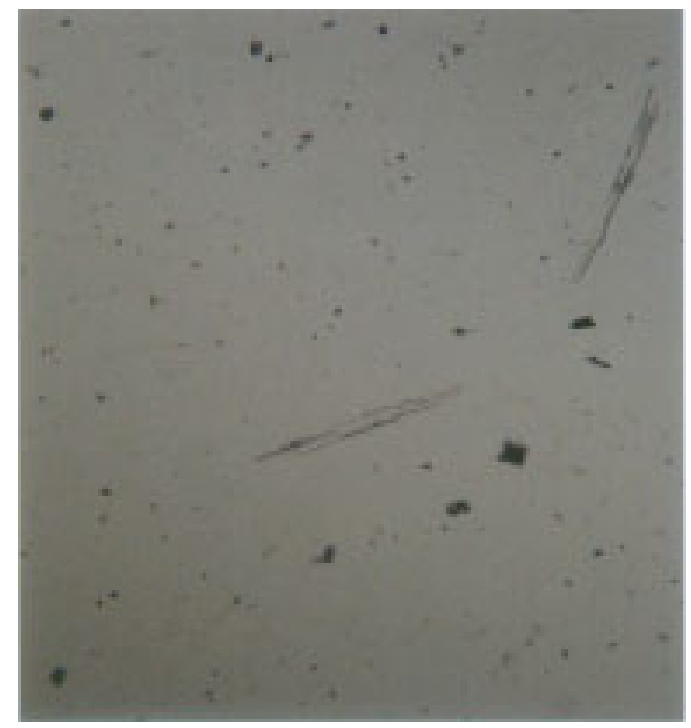

Fig. (1) : Thick needle like crystals (fattening broiler chickens) x 200 .

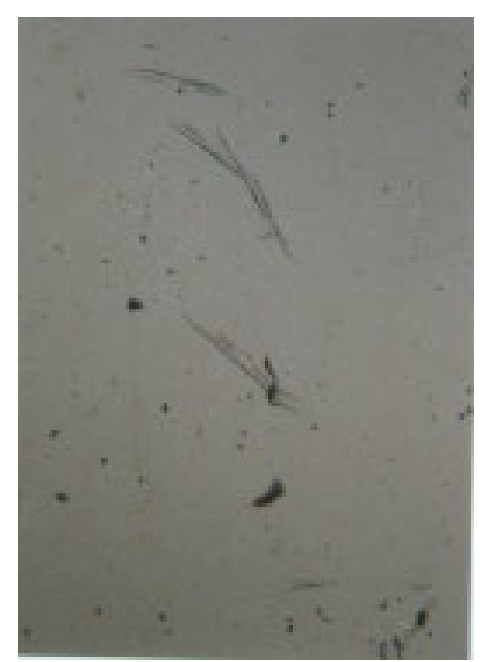

Fig. (2) : Thick Needle - like crystals (fattening broiler chickens) x 200 .

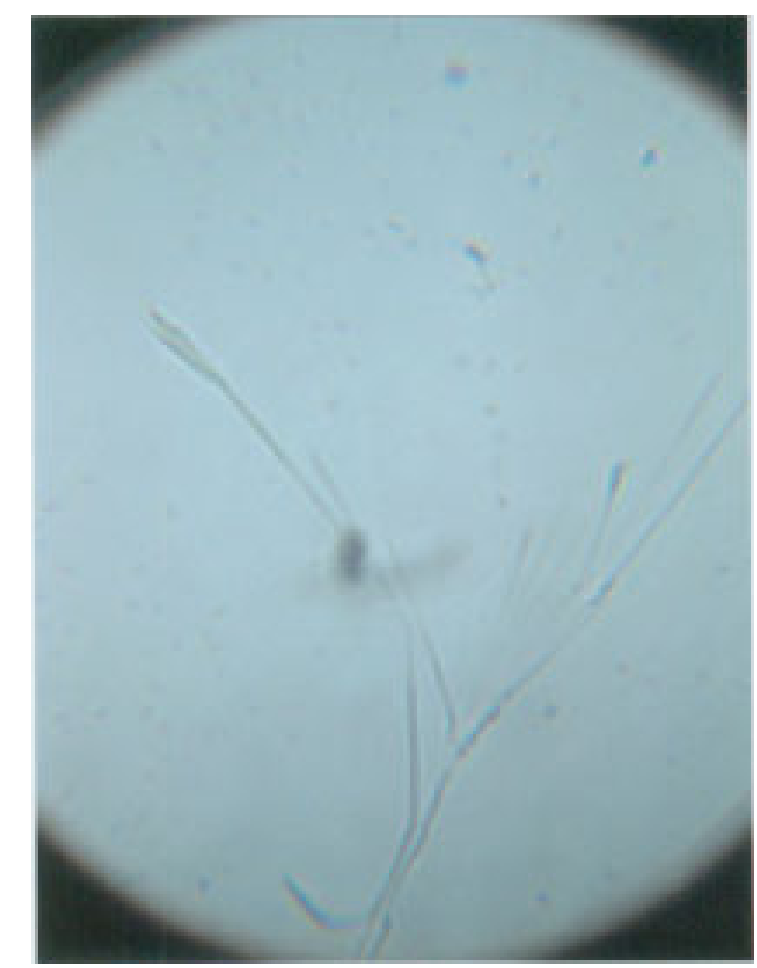

Fig. (3) : Contacted crystals (of two crystals : long crystal (the left) + frond shape (the right) (fattening broiler chickens) $\mathrm{x} 400$. 


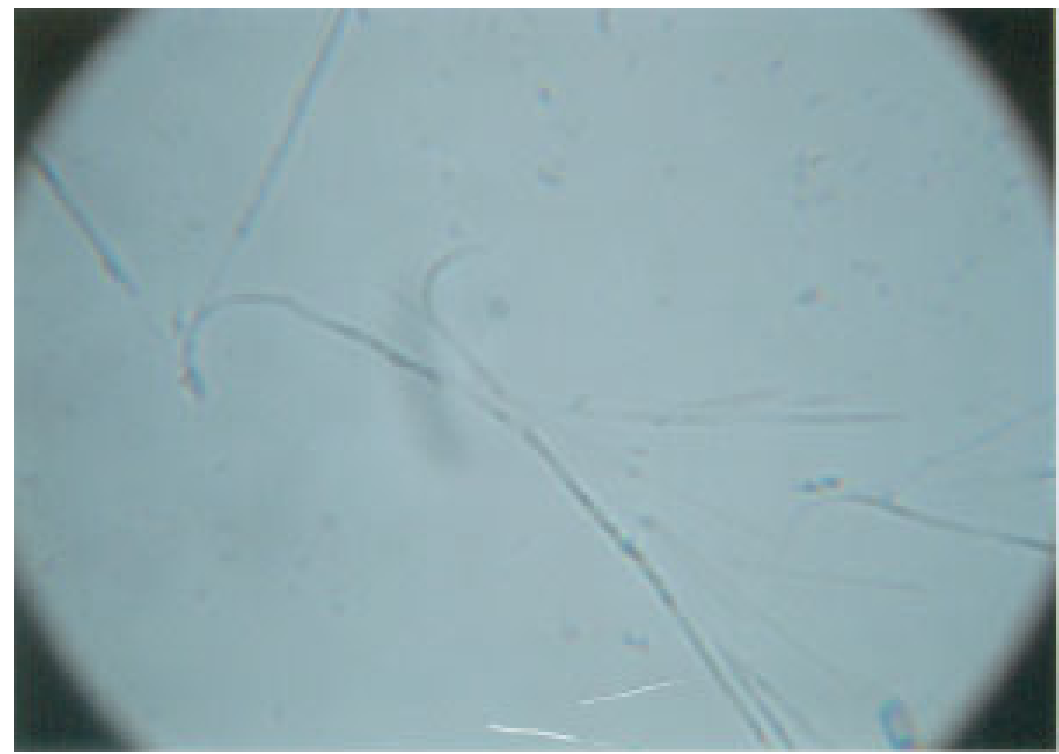

Fig. (4) : Contacted myosin crystals of two crystals (in the left) and two short branched stem- like crystal (in the right) (Fattening broiler chickens) (x400).

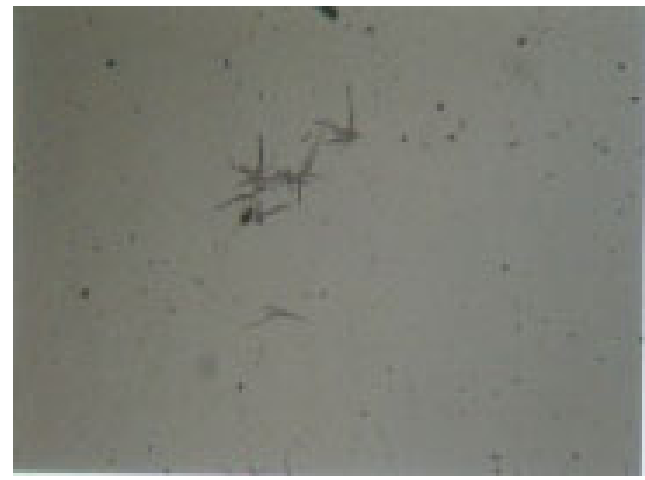

Fig. (5) : Branched point like crystals (Native broiler chickens)(x200).

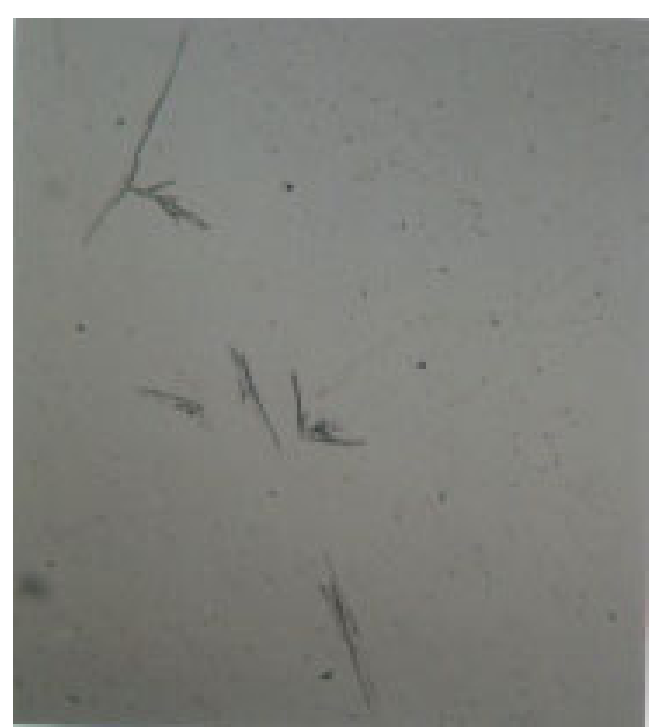

Fig. (6) : Branched point like crystal (the central right) most of the other crystals are thick needle crystals (Native broilers chickens) (x200). 


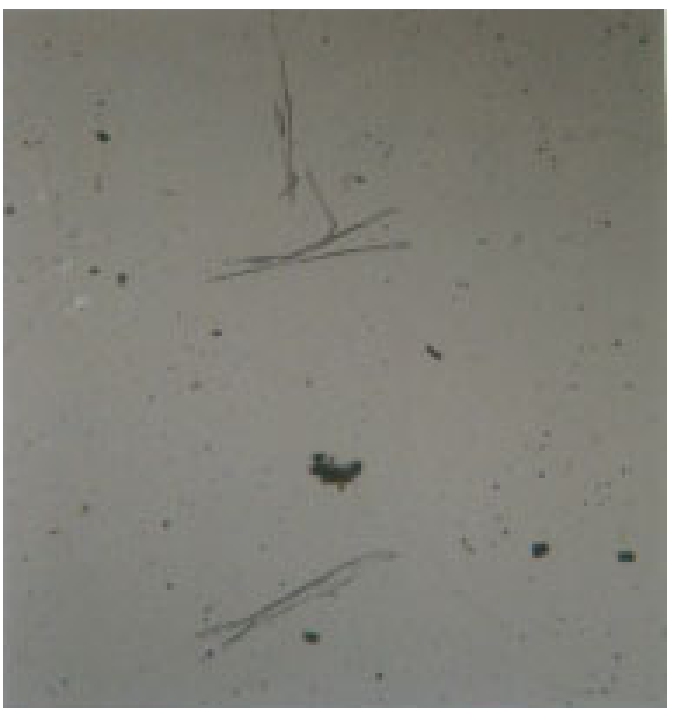

Fig. (7) : Thick Needle crystals. (lower and upper) and contacted crystals (The medium) (Native broilers) (x200).

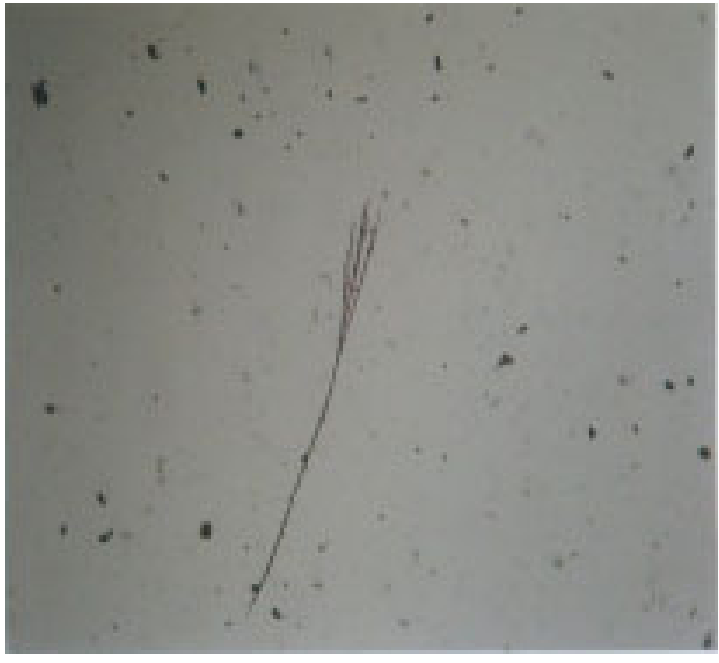

Fig. (8) : Long branched stem like crystal (pigeon) (200) .

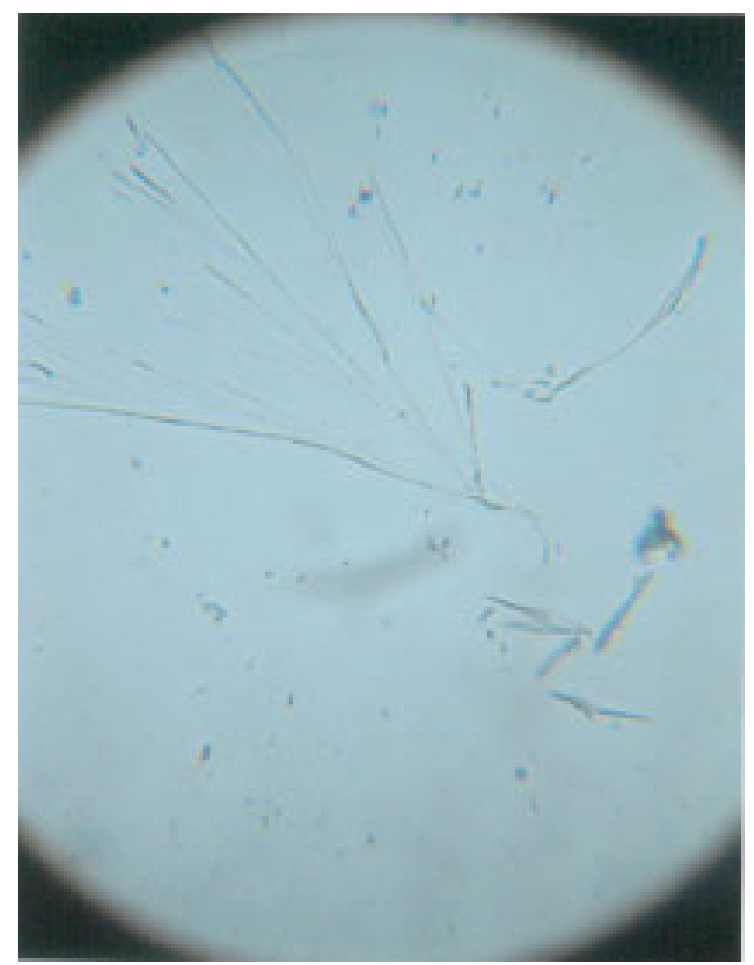

Fig. (9) : Long branched stem like crystal (The small upper right one), short branched stem like crystals (the larger Left) and two thick needle crystals (the lower right) (Pigeons) (x400). 


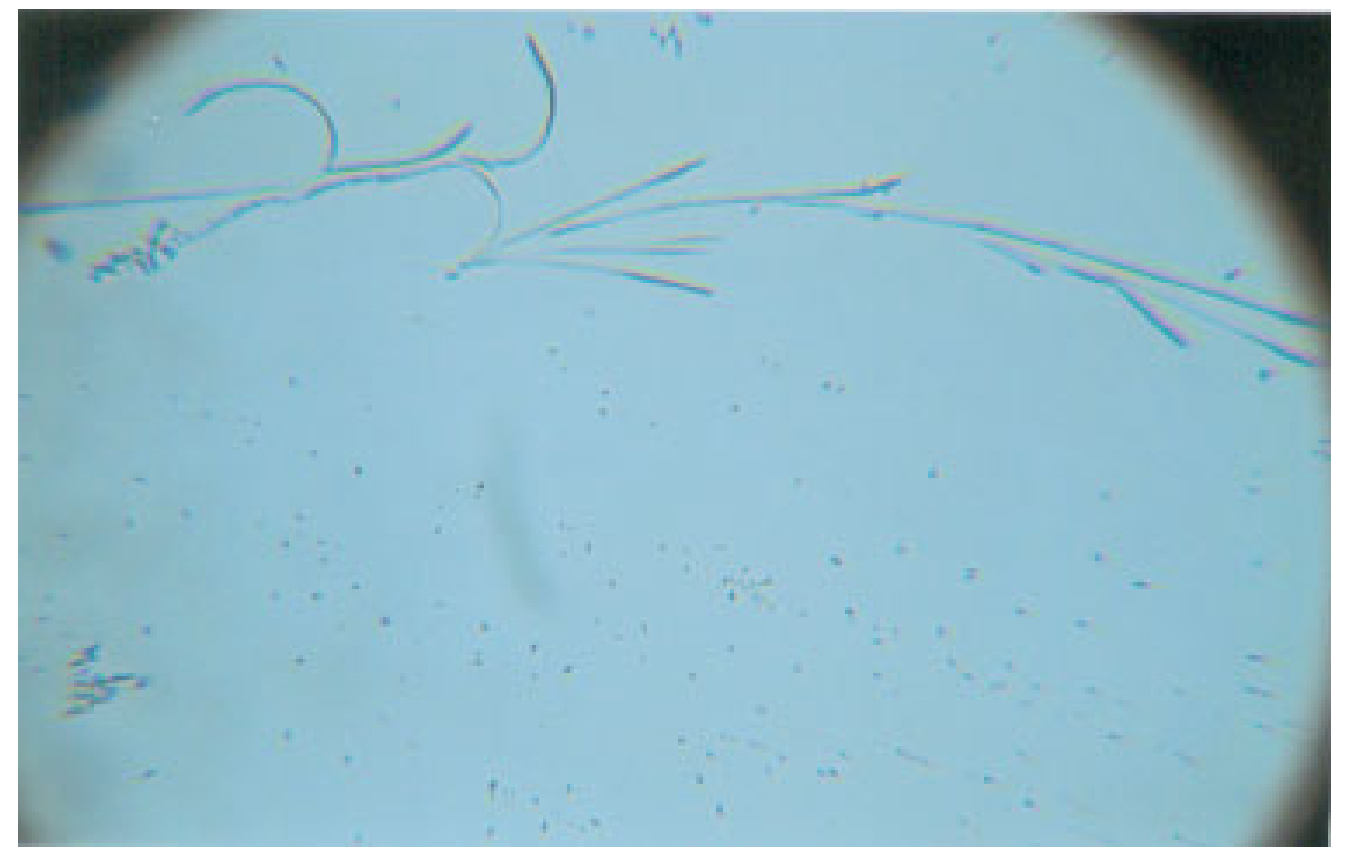

Fig. (10) : Long branched stem like crystal (the right) and Contacted crystal (the left) (pigeons) (x400).

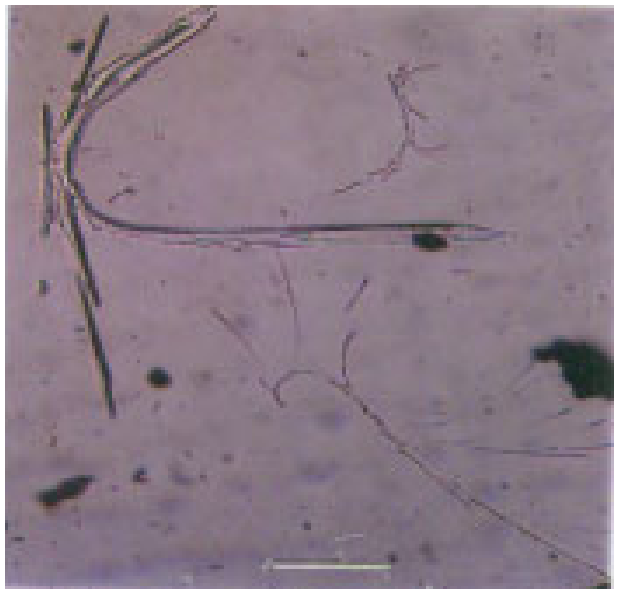

Fig. (11) : K-litter shape like crystals (left), two long branched stem like crystals (right lower and upper thin shapes) (pigeons) (x400).

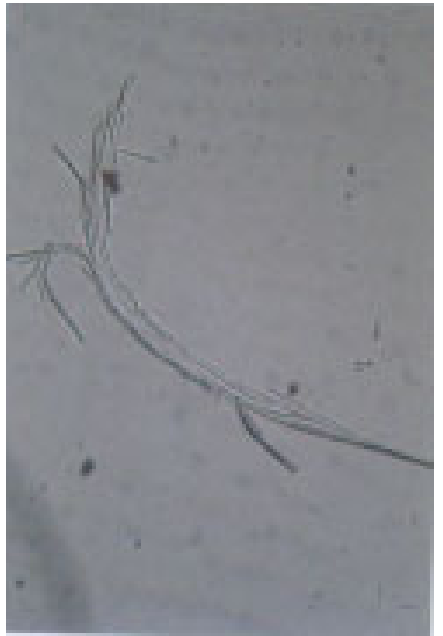

Fig. (12) : X- litter shape like crystal (Ibises) $(\mathrm{x} 400)$. 


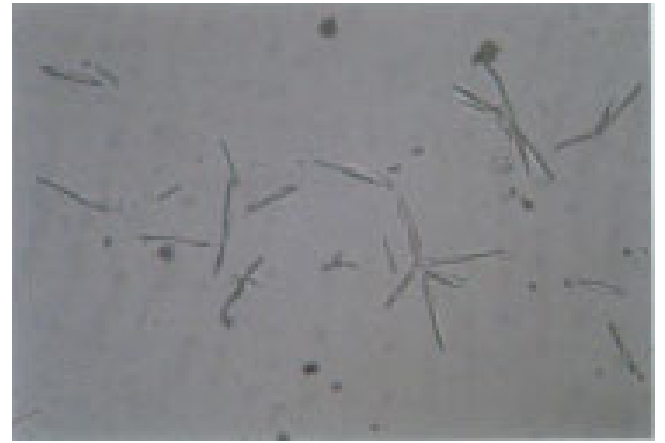

Fig. (13) : X- litter shape like crystals, and thick needle like crystals (Ibises) (x200).

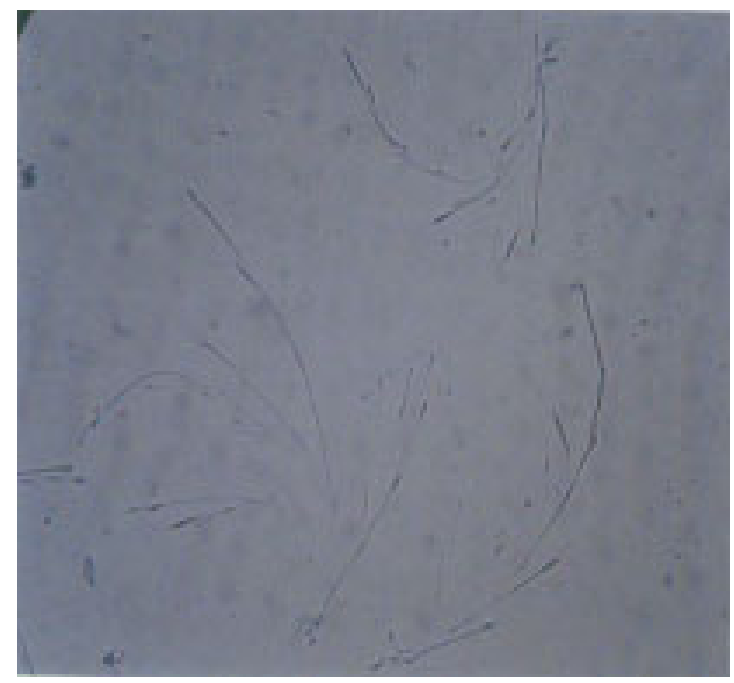

Fig. (15) : Two (short branched stem- like crystals) (the lower upright and the higher inverted) and Frond shapelike crystal (the right lower) (Ducks) (x400).

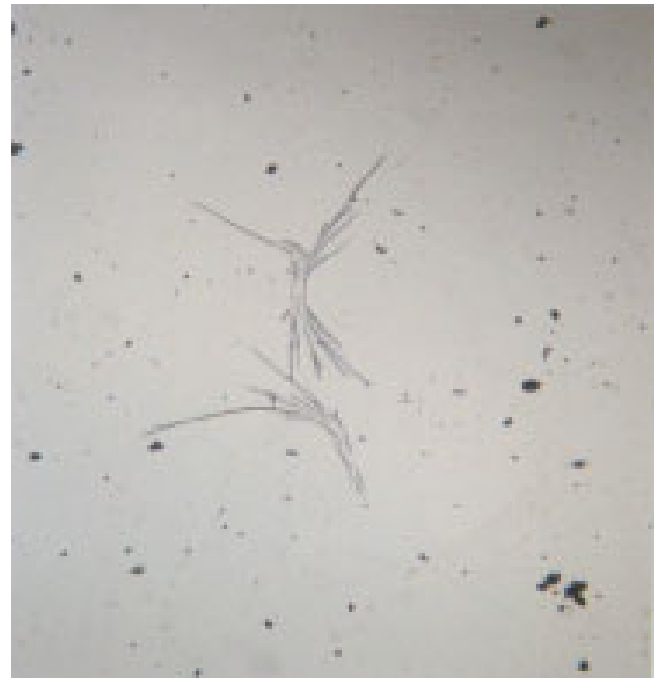

Fig. (14) : X- litter shape like crystals (the upper) and contacted crystals (Lower) (Ibises) (x200).

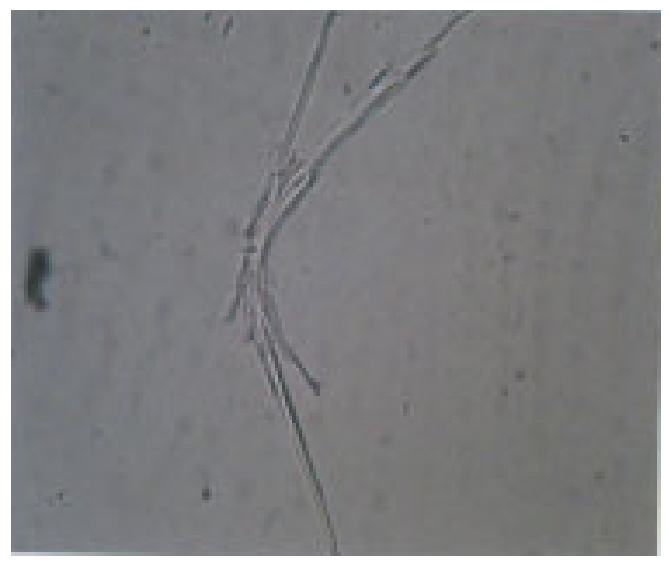

Fig. (16) : K- litter shape-like crystals (Ducks) (x400) 


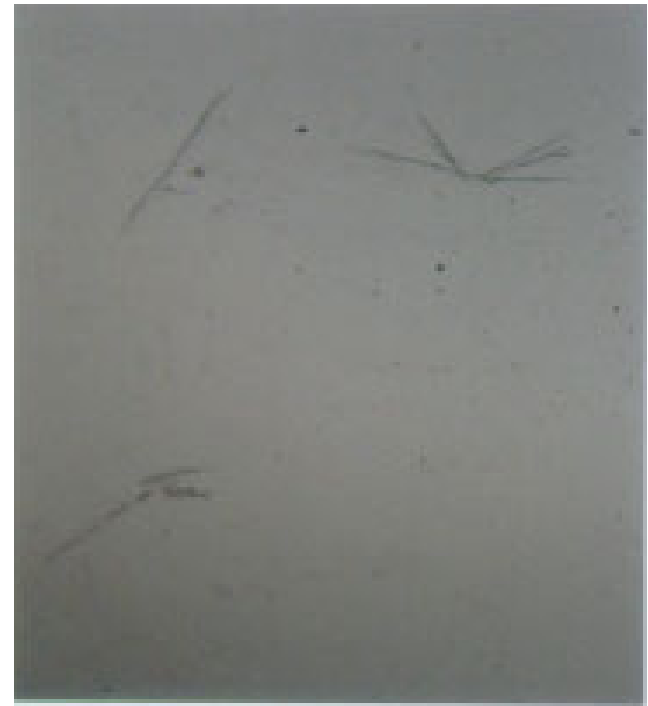

Fig. (17) : Two Thick needle-like crystals (the left lower and upper) and K- litter shape like crystals (the right) (Ducks) (x200)

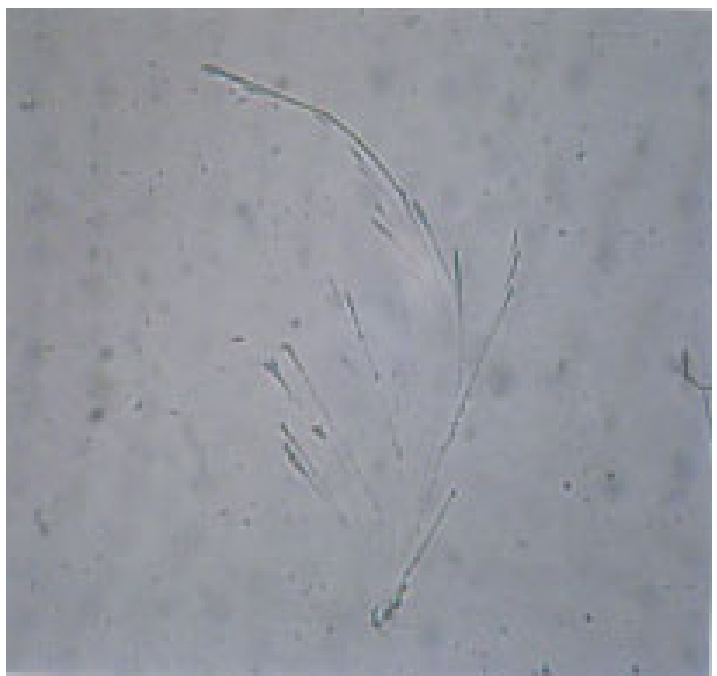

Fig. (19) : Short branched stem- like crystal (Ducks) (x400).

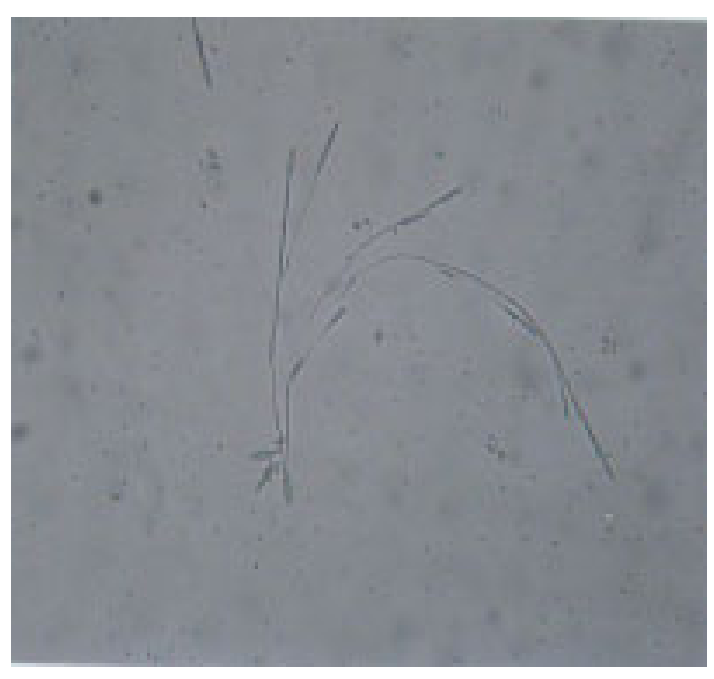

Fig. (18) : Short branched stem-like crystals (Ducks) (x400).

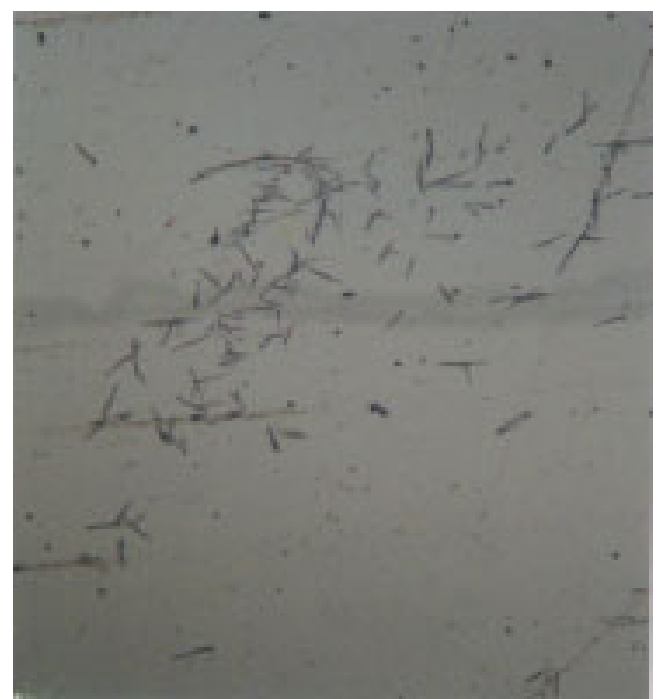

Fig. (20) : Small needle like crystals (Ducks) (x200). 


\section{REFERENCES}

Charles, B. (1966) : Crystals, their role in nature and in science, 2nd. Printing, Academic press Inc., New York and London.

Gyorgyi, S. (1943) : The crystallization of myosin and some of its properties and reactions. Studies Instit. Med. Chem. Univ. Szeged (3): 76-85.

Harper, H.; Rodwell, V. and Mayes, P. (1979) : Review of physiological Chemistry, $17^{\text {th }}$. Ed., Middle East Ed. Lange Medical Publications.

Hartshorne, N. H. Stuart, A. (1952) : Crystals and the polarizing microscope, London Edwards Arnold Co., Butler and Tanner LTD, France and London.

Helal, A. D. (1987) : Identification of Different types of Meat for Medicolegal purposes., M. V. Sc. Thesis, Forensic Medicine and Toxicology, Faculty of Vet. Medicine, Cairo University.

Huxley, H. E. and Zubay, G. (1960) : J. Mol. Biol.(10): Cited by Sherman et.al. (1981).

Moose, C. (1993) : Cold Spring harbor Symp. Quant. Biol.(37):93-95, Cited by Siemankowski and Zobel (1976) :

Oser, B. L. (1979) : Hawk's Physiological Chemistry, $14^{\text {th }}$. Ed., Tata, MC Grow, Hill
Publishing Co. LTD., New Delhi.

Offer, G. (1973) : Cold spring Harb. Symp.Quant. Biol. (37):87-93, Cited by Siemankowski and Zobel(1976).

Rayment, I. and Winkelmann, D. A. (1984) : Crystallization of Myosin subfragment-1. Proc. Natl. Acad. Sci. USA, 81(14) : 4378-80.

Siemankowski, R. F. and Zobel, C. R. (1976) : Comparative studies on the structure and aggregative properties of the myosin molecule, 111.the in vitro aggregative properties of the Lobster myosin Molecule. Biochem. Biophys. Acta, 420(2): 406-416.

Sherman, B. B.; Orlova, E. A.; Terzyan, S. S.; Kleine, R. and Kiselev. (1981) : On the negative staining of the protein crystal structure. Ultramicroscopy (7): 131-138.

Toma, M. and Berl., S. (1981) : Structural characterization of myosin from brain. Eur. J.cell Biol., 28(1): 122-129.

Unwinn, P. N. T. (1975-A) : J.Mol. Biol. (94):425, Cited by Sherman et. al. (1981). Unwinn, P.N.T(1975-B): J. Mol. Biol., (98) : 235, Cited by Sherman et.al.(1981)

Wachaberger, P. B. and Pepe, F. A. (1980) : Interaction between skeletal and uterine muscle myosins and light meromyosins. J. cell. Biol., 85 (1): 33-41. 
Helal, A. D.; et al...

الملخص العربى

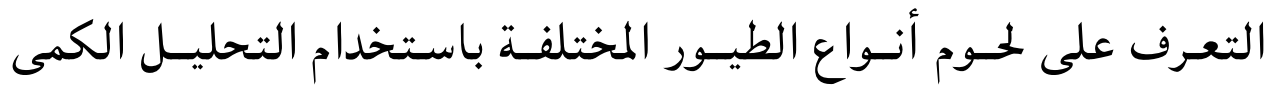

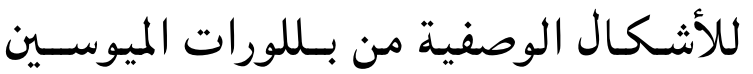

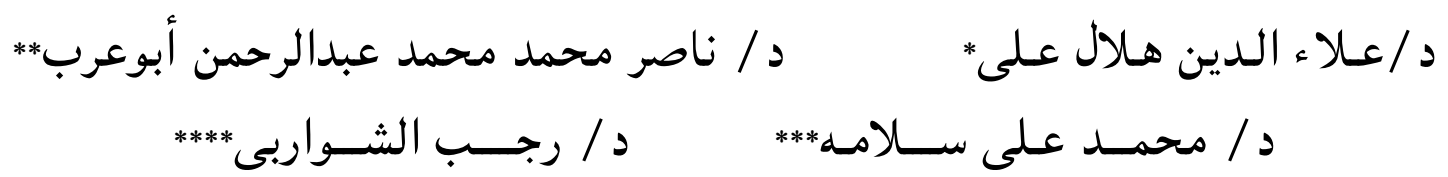

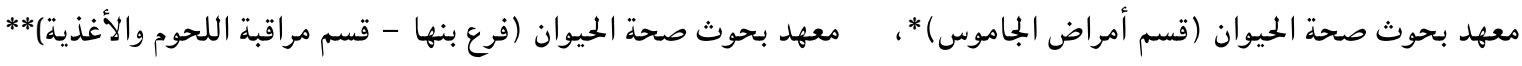

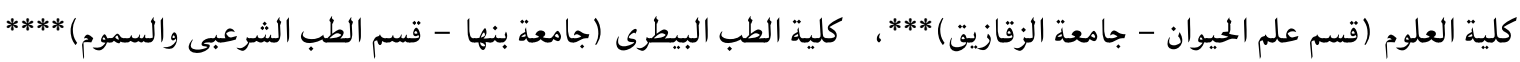

الميوسين هو أحد وأهم بروتين إنقباضى فى العضلات وقد أمكن تحضير بللورات من الميوسين المستخلص من العضلات على شكل بللورات

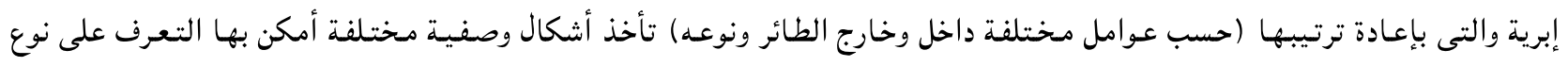

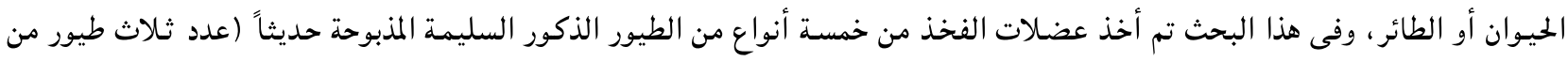

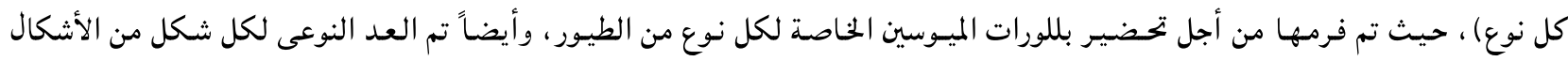

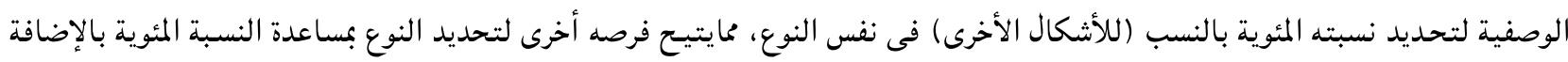

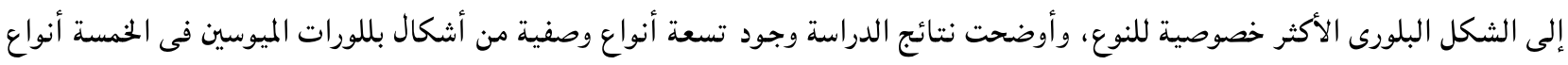

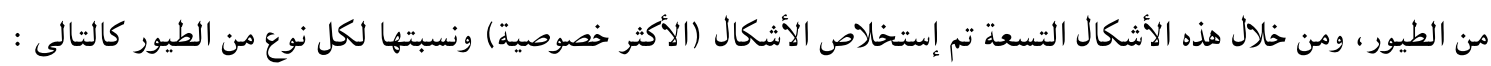
دجاج التسمين : بللورات الميوسين شبيهة بالإبر الكبيرة (18.9\% ) ، وبللورات الميوسين المتلامسة (,5.22\%) ، وفى الدجاج المصرى

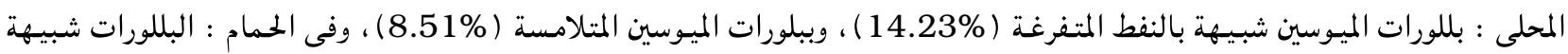

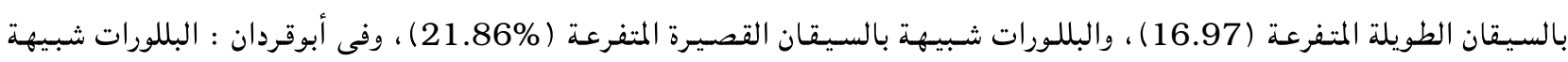

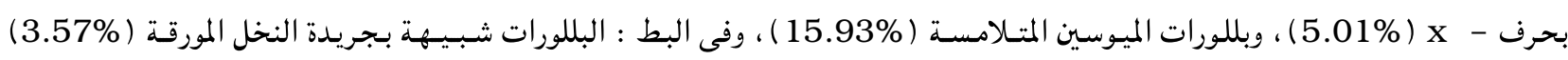
والبللورات شبيهة بالسيقان القصيرة المتفرعة (20.06\%) ، ويوجد النوع التاسع من البللورات وهى بللورات الميوسين شبيهة بالإبر الصغيرة

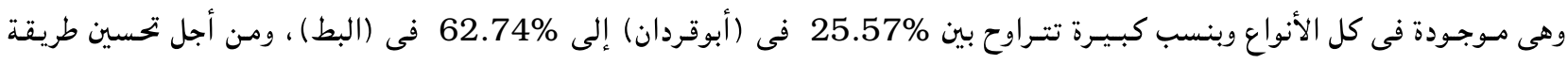

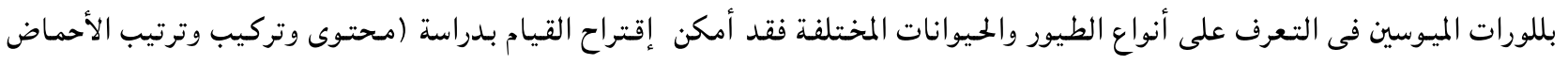

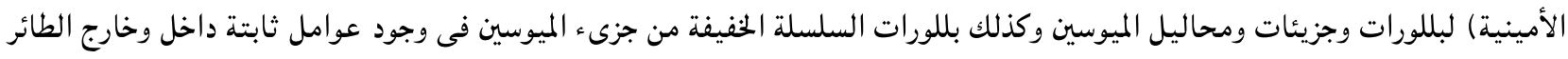

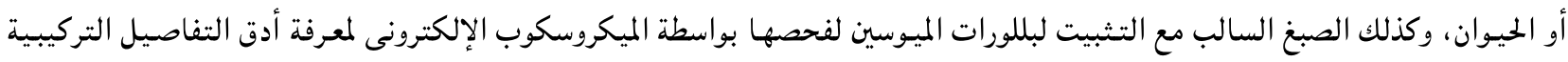

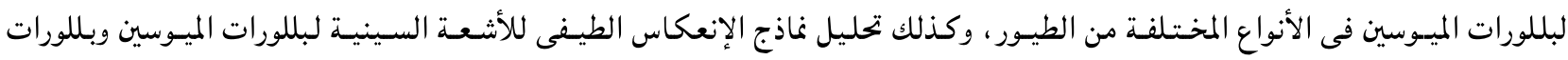

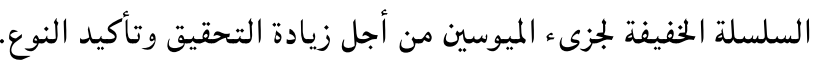

